\title{
Deciphering a potentially hyperdiverse diet of wandering spider, (Phoneutria boliviensis; Araneae: Ctenidae) by DNA metabarcoding of gut contents
}

\author{
Diego Sierra ${ }^{1}$, Giovany Guevara ${ }^{1}$, Lida Franco Perez ${ }^{2}$, Arie van der Meijden ${ }^{3}$, Julio \\ Gonzalez Gomez ${ }^{1}$, Juan Valenzuela Rojas ${ }^{4}$, and Carlos Prada Quiroga ${ }^{4}$ \\ ${ }^{1}$ Universidad del Tolima Facultad de Ciencias \\ ${ }^{2}$ Universidad de Ibague \\ ${ }^{3}$ Affiliation not available \\ ${ }^{4}$ Universidad del Tolima
}

September 11, 2020

\begin{abstract}
Arachnids are the most abundant land predators. Despite the importance of their functional roles as predators and the of necessity to understand their diet for conservation and nutrient fluxes, the trophic ecology of many arachnid species is not fully understood. In the case of the wandering spider, Phoneutria boliviensis F. O. Pickard-Cambridge, 1897, only selected field and laboratory observational studies about their diet exist. By using a DNA metabarcoding approach, we compared the prey found in the gut content of males and females from three distant Colombian populations of P. boliviensis. By DNA metabarcoding of the cytochrome c oxidase subunit I (COI), we detected and identified 234 prey records belonging to 96 operational taxonomic units (OTUs), as prey for this wandering predator. Our results broaden the known diet of P. boliviensis with at least 75 prey taxa not previously registered in fieldwork or laboratory experimental trials. These results suggest that P. boliviensis feeds predominantly on invertebrates (Diptera, Lepidoptera, Coleoptera and Orthoptera) and opportunistically on small squamates. Intersex and interpopulation differences are observed. Assuming that prey preference does not vary between populations, these differences are likely associated with a higher local prey availability. Finally, we suggest that DNA metabarcoding can be used for evaluating subtle differences in the diet of distinct populations of P. boliviensis, particularly when predation records in the field cannot be established or quantified using direct observation
\end{abstract}

Deciphering a potentially hyperdiverse diet of wandering spider, (Phoneutria boliviensis; Araneae: Ctenidae) by DNA metabarcoding of gut contents

Diego Sierra Ramírez ${ }^{1}$, Giovany Guevara ${ }^{2}$, Lida Marcela Franco Pérez ${ }^{3}$, Arie van der Meijden ${ }^{1,4}$, Julio César González-Gómez ${ }^{1,3}$, Juan Carlos Valenzuela-Rojas ${ }^{1}$, Carlos Fernando Prada Quiroga ${ }^{1,{ }^{*}}$

${ }^{1}$ Grupo de Investigación Biología y Ecología de Artrópodos (BEA), Corporación Huiltur, Neiva, Huila y Facultad de Ciencias, Universidad del Tolima, Altos de Santa Helena, Ibagué 730001, Colombia

${ }^{2}$ Grupo de Investigación en Zoología (GIZ), Facultad de Ciencias, Universidad del Tolima, Altos de Santa Helena, Ibagué 730001, Colombia

${ }^{3}$ Facultad de Ciencias Naturales y Matemáticas, Universidad de Ibagué, Carrera 22 calle 67, Ibagué 730001, Colombia

${ }^{4}$ CIBIO Research Centre in Biodiversity and Genetic Resources, InBIO, Universidade do Porto, Campus Agrário de Vairão, Rua Padre Armando Quintas 7, 4485-661 Vairão, Vila do Conde, Portugal 
Correspondence: Carlos F Prada Universidad del Tolima, Altos de Santa Helena, Ibagué 730001, Colombia. Email:cfpradaq@ut.edu.co

Abstract

Arachnids are the most abundant land predators. Despite the importance of their functional roles as predators and the of necessity to understand their diet for conservation and nutrient fluxes, the trophic ecology of many arachnid species is not fully understood. In the case of the wandering spider, Phoneutria boliviensis F. O. Pickard-Cambridge, 1897, only selected field and laboratory observational studies about their diet exist. By using a DNA metabarcoding approach, we compared the prey found in the gut content of males and females from three distant Colombian populations of P. boliviensis . By DNA metabarcoding of the cytochrome $c$ oxidase subunit I (COI), we detected and identified 234 prey records belonging to 96 operational taxonomic units (OTUs), as prey for this wandering predator. Our results broaden the known diet of $P$. boliviensiswith at least 75 prey taxa not previously registered in fieldwork or laboratory experimental trials. These results suggest that $P$. boliviensis feeds predominantly on invertebrates (Diptera, Lepidoptera, Coleoptera and Orthoptera) and opportunistically on small squamates. Intersex and interpopulation differences are observed. Assuming that prey preference does not vary between populations, these differences are likely associated with a higher local prey availability. Finally, we suggest that DNA metabarcoding can be used for evaluating subtle differences in the diet of distinct populations of $P$. boliviensis, particularly when predation records in the field cannot be established or quantified using direct observation.

Keywords: Predator-prey interaction, gut content metabarcoding, molecular diet analysis, diet, Phoneutria, prey detection.

\section{INTRODUCTION}

Understanding the contribution of predators in shaping the structure of ecological communities is a central issue in ecology (Lima 1998; Schmitz 2007; Seibold, et al. 2018). Therefore, predator-prey interactions are a main driver of natural selection, population dynamics, food web structure, community assemblages, and ecosystem function (Portalier, et al. 2019; Severtsov and Shubkina 2015; Start, et al. 2020). Spiders are among the most abundant predators in terrestrial ecosystems, playing an important role in the controlling prey species populations (Betz and Tscharntke 2017; Michalko, et al. 2019; Pekar, et al. 2011; Pusceddu, et al. 2018). Almost all spiders are carnivores, feeding predominantly on arthropods including, to a lesser extent, other spiders (Birkhofer and Wolters 2012; Nyffeler 1999; Pekar and Toft 2015). Very rarely nonarthropod prey are consumed as a supplement to the arthropod diet (Foelix 2011; Nyffeler, et al. 2016; Symondson, et al. 2002). However, this appears to be relatively frequent in some spider families which include large-sized species, such as Theraphosidae, Ctenidae, Lycosidae, and Pisauridae, among others (Hazzi 2014; Valdez 2020).

Predators in their search for food sources can develop narrow (stenophagous) or broad (euryphagous) eating habits (Pekar and Toft 2015). In the case of spiders, the stenophagous specialists possess adaptations for the capture of large focal prey, minimizing handling time, and live in proximity to their prey so they can minimize foraging time. As a result, the capture time is much shorter than in euryphagous species (Garcia, et al. 2018; Michalek, et al. 2017; Pekar, et al. 2011; Pompozzi, et al. 2019). On the other hand, euryphagous spiders, which select prey smaller than their body and must thus capture more items of prey, could minimize foraging time by shortening the duration of consumption of each item of prey (Garcia, et al. 2016; Pompozzi, et al. 2019). Indeed, recent studies showed that cursorial obligatory stenophagous species selected larger prey and fed for a significantly longer time, extracting significantly more mass than euryphagous spiders (Garcia, et al. 2018; Michalek, et al. 2017).

Spiders of the genus Phoneutria, popularly known as "Banana spiders" or "wandering spiders", are restricted to South America and they are essentially wandering, nocturnal spiders. This genus represents one of the main groups of medically important spiders in South America because of their defensive behavior, anthropogenic habits, and potent venom (Hazzi 2014; Valenzuela-Rojas, et al. 2019; Vetter and Isbister 2008). Recent records on the diet of $P$. boliviensis suggest these spiders prey on several arthropod species 
but also consume vertebrates, mainly reptiles and anurans (Valenzuela-Rojas, et al. 2019). In addition, mammals and birds have occasionally been reported as prey in other Phoneutria species, suggesting they are likely a generally euryphagous genus (Bucherl, et al. 2013). Intersexual differences have been reported in the production of venom of Phoneutria. For example, experiments with $P$. nigriventer and $P$. boliviensis showed that there is greater venom production in females than in males (Estrada-Gomez, et al. 2015; Herzig, et al. 2002; Valenzuela-Rojas, et al. 2019), which could indicate a possible difference in prey between the sexes. However, recent laboratory observations on P. boliviensis showed no difference in prey acceptance between males and females (Valenzuela-Rojas, et al. 2019). In this same study venom of males and females was found to be more effective against vertebrate (geckos) and spider prey than other prey types.

Spiders feed on the pre-digested fluids of their prey through external digestion and ingest nutrients only in liquid form. Following ingestion of liquefied material through the esophagus and sucking stomach, the food enters the midgut which branches into highly complex diverticula extending throughout the prosoma and into the legs (Foelix 2011; Macias-Hernandez, et al. 2018). Consequently, digestion takes place in many different parts of the body and dissecting the whole gut is nearly impossible due to its complexity and extent (Macias-Hernandez, et al. 2018). This condition restricts field studies of spider diet to direct observation, stable isotope analysis, and molecular analysis (Birkhofer, et al. 2017; Jackson, et al. 2001; Lafage, et al. 2020; Pompanon, et al. 2012).

Molecular gut content analysis is a valuable tool for characterizing trophic interactions. DNA-based methods possess a range of advantages over other approaches in diet analysis (Lafage, et al. 2020; Sheppard and Harwood 2005). The inherent bias and arduous process of taxonomic determination by field work observation has led to an increased use of molecular techniques to investigate the diet of spiders, of which DNA metabarcoding is currently one of the most accurate and efficient for the analysis of generalist polyphagous diets, achieving very good results in ecological studies on multiple species of arachnids with euryphagous diets (Pinol, et al. 2019). Likewise, DNA metabarcoding workflows are intrinsically different from conventional invertebrate identification approaches in that they use short DNA sequences as a proxy for species detection (Liu, et al. 2020).

We recently investigated the feeding preferences and related role of the venom of the wandering spider $P$. boliviensis (Valenzuela-Rojas, et al. 2020; Valenzuela-Rojas, et al. 2019), a widely distributed spider species on the American continent inhabiting several ecosystems in South America, spread across Bolivia, Paraguay, Peru, Ecuador, Brazil, and Colombia (Estrada-Gomez, et al. 2015; Hazzi 2014). To further understand the ecological and evolutionary interactions among trophic ecology, venom composition and predatory behavior in this species, we study the diet. The objective of this study, beyond knowing what $P$. boliviensiseats, was to test whether there are interpopulation and intersexual differences in diet, through the technique of DNA metabarcoding of gut contents. To our knowledge, this is the first study using this molecular technique for detecting the diet of $P$. boliviensis .

\section{MATERIALS AND METHODS}

\section{Collection and locations}

Sixty adult specimens of $P$. boliviensis were used for DNA metabarcoding of the entire gut contents. Twenty individuals (ten females and ten males) of the spiders came from three Colombian localities each, distant by an average of $300 \mathrm{~km}$ : Barbosa (Antioquia; 6deg40' 54.7” N, 75deg41' 10.4”W), Oporapa (Huila; 2deg01'40.5” N, 75deg59'43"W) and Ibague (Tolima; 4deg32'22.3"N, 75deg05'37.1”W). Spiders were collected from July 2019 to September 2019 (Figure 1). Locations were selected based on the previous distribution reports for the species in Colombia, and accessibility (Estrada-Gomez, et al. 2015; Valenzuela-Rojas, et al. 2020; Valenzuela-Rojas, et al. 2019).

Selected adult individuals were opportunistically collected during one night by randomly following cardinal transects of $500 \mathrm{~m}$ between 20:00 and 04:00 h for three nights. However, most collection was done in what we found to be the "peak hours" of activity of the species (between $00.00-03.00 \mathrm{~h}$; JCV-R and JCG-G, Pers. Obs.). For each individual, elevation, temperature, relative humidity and mass (g) was recorded 
(Supplementary Table S1). At each locality, in addition to the 20 specimens, three more individuals were taken for standardization of the DNA metabarcoding technique. After euthanized by freezing, the collected individuals were stored in separate Falcon(c) tubes in $96 \%$ alcohol and transported to the Biology Laboratory of the University of Ibague (Ibague, Colombia). Subsequently, $96 \%$ alcohol washes were performed to remove impurities. Later, the distal parts of the legs (tarsus and metatarsus) were removed, since they do not contain gut diverticula (Macias-Hernandez, et al. 2018). In all cases, dissection procedures were conducted using forceps and scissors, flame sterilized after each dissection to prevent cross contamination. We performed all laboratory activities on a clean and sterilized laboratory bench. The dissected parts were then subjected to DNA extraction separately (Macias-Hernandez, et al. 2018). Tissue samples were submitted to the standard procedures of the Canadian Centre for DNA Barcoding (CCDB) for sequencing the cytochrome $c$ oxidase subunit I gene (COI), the standard marker for the identification of most animals (Pentinsaari, et al. 2020). We used the Qiagen DNEasy Tissue kit for DNA extraction under manufacturer's conditions and used Bioline Plant TAQ to amplify PCRs.

\section{Preliminary assays and samples processing}

Since dissection of the highly diverticulated gut is difficult, we performed three preliminary assays to determine which sampling of the spider's body (prosoma, prosoma+opisthosoma or the entire individual except tarsus and metatarsus) yielded the most prey sequences (Macias-Hernandez, et al. 2018). We used the primers dgHCO and mlCOIntF for PCR and sequencing (Leray, et al. 2013). Once these conditions were determined, DNA extraction was performed on the 60P. boliviensis samples from the three selected locations, using the blocking primer pair noSPI blocking Primer 5'TACACGACGCTCTTCCGATCTTCATTTYCCHCGWATAAAYAAYATAAG3' and dgHCO1 5'CAGACGTGTGCTCTTCCGATCAGGAGTAAACTTCAGGGTGACCAAARAAYCA3‘

\section{Sequencing and DNA Metabarcoding}

The metabarcoding of the $P$. boliviensis samples was performed with the Illumina platform, where the pairend-merging was done using USEARCH v11.0.667 (Edgar 2010) and the trimming processing was done in a custom program using Python 2.7.15 to obtain the reads. The process of sequencing and quality control of the reads was carried out by the company AIM (www.aimethods-lab.com) following standard protocols (Kress and Erickson 2007; Sang, et al. 1997). Sequences with a length of less than 300pb were eliminated (with a maximum expected error of 1\%) using FastQC version 0.11.8 (de Sena Brandine and Smith 2019). In addition, singletons, unique sequences and chimera sequences were filtered using VSEARCH 2.9.1 (Rognes, et al. 2016) to generate the final FASTQ files by sample, following the protocols proposed by Leidenfrost et al and Liu et al (Leidenfrost, et al. 2020; Liu, et al. 2020). After quality filtering, a total of 2,410,269 pair-end reads were obtained.

Sequences were blasted against the complete sequence database of the Barcode of Life Data systems (BOLD) in order to find the closest matches using the BOLD Identification Engine (http://www.boldsystems.org) (Ratnasingham and Hebert 2007). Taxon nomenclature follows the catalogue used in the BOLD and NCBI databases (Federhen 2012). Based on the FASTQ files for each individual, 256 operative taxonomic units (OTUs) were identified.

Based on these OTUs, different filters according to standard exclusion criteria for this technique were applied (Deagle, et al. 2019; Lafage, et al. 2020), in which sequences with the following characteristics were eliminated: a) all reads representing fewer than $0.01 \%$ of the total number of reads per sample were removed from the analysis, b) sequences that corresponded to environmental DNA or intestinal microbiota, and c) OTUs that did not correspond to the geographical distribution of $P$. boliviensis . Once these filters were applied, the OTUs were identified at the species taxonomic level to those sequences with identity at [?] 97\%, genus with [?] 95\%, family with $90 \%$ and order [?] 75\%. Additionally, BINs (Barcode Index Numbers) were used to identify sequence clusters within the database, correlating with species in $98 \%$ of all cases (Lafage, et al. 2020). After OTU filtering, a total of 105,583 sequences were obtained, corresponding to 96 OTUs. In order to not underestimate the total reads, a standardization was made for each sample (percentage of 
reads per sample).

\section{Data analyses}

To test differences in body mass ( $\mathrm{g}$ ) between the sexes and populations, the mass of males and females were initially compared using the Wilcoxon-Mann-Whitney Test with the package "coin", and the mass between populations using the Kruskal-Wallis Test with the package "dplyr" in R version 4.0.2. In addition, a Wilcoxon post-hoc analysis with Bonferroni adjustment was used (R Development Core 2018), and the mass of the different spiders was correlated with the estimated size of the different potential prey obtained using the bugGuide database (https://bugguide.net/node/view/15740) (Bartlett 2003). Table Supplementary S1). The data on the diet of Phoneutria was analyzed separately by sex and population. A Chi-square goodness-of-fit test was applied to compare the ratio of number of reads between sexes and populations with Minitab 17 (Arend 2010). Additionally, the confidence intervals between sexes under the binomial distribution were corroborated with Statpages (https://statpages.info). Bipartite prey-spider reads interaction network diagrams by sex and populations were created with Sankeymatic (http://sankeymatic.com/); accessed on March 2020.

We also compared the richness of prey (i.e., OTUs that result after of applying all filtering procedures for the reads) detected for each of the three Colombian populations of $P$. boliviensis using sample-based rarefaction curves (Hsieh, et al. 2016) by calculating the Hill's numbers by means the q parameter ( $\mathrm{q} 0=$ species richness) (Chao, et al. 2014). The confidence intervals for the obtained curves were determined using the bootstrap method with 1000 resampling replicates. All analyses and visualizations were performed in $\mathrm{R}$ version 3.5.2 (R Development Core 2018), using the iNEXT package (Hsieh, et al. 2016).

\section{RESULTS}

2. Mass of spiders

Our results show that the females have a mass of $3.79+-0.21 \mathrm{~g}$ (mean +- standard error), with females weighing from 1.86 to $6.08 \mathrm{~g}$, while males weigh $2.25+-0.17 \mathrm{~g}$, with individuals weighing from 1.01 to $4.64 \mathrm{~g}$. The difference in mass between the sexes was highly significant $(\mathrm{P}<0.01)$ (Supplementary Table S1 and Figure S1, section a). When analyzing the weight by locality, also significant differences were found $(\mathrm{P}=$ 0.027). We found that spiders from the Ibague sampling zone tend to be larger (mean of $3.61 \mathrm{~g}$ ) compared to those from the Oporapa and Barbosa populations (mean of 2.62 and $2.82 \mathrm{~g}$, respectively). These results are summarized in the Supplementary Figure S1, section b. No correlation $\left(R^{2}=0,003\right)$ was observed between fresh spider mass $(\mathrm{g})$ and prey size $(\mathrm{mm})$.

\section{DNA metabarcoding analysis in Phoneutria boliviensis}

Preliminary analyses with the blocking primers identified that the optimal annealing temperature was 48degC. We also found that the Prosoma+Opisthosoma region contained the higher prey stomach content. We used these conditions for the processing of the $60 \mathrm{P}$. boliviensissamples from the three sampled locations for metabarcoding.

Of the 60 samples analyzed, and after applying all the filters, 57 had at least one prey (for two Barbosa spiders and one Ibague spider, no prey was observed). We identified 96 different OTUs belonging to 10 different taxonomic orders (9 invertebrate and 1 vertebrate). Arthropods contributed the largest portion of the diet (97.9\% of prey DNA recovered). The taxonomic orders with the greatest number of species represented in the diet (77\% of prey DNA recovered) included Diptera (23), Coleoptera (20), Lepidoptera (17) and Orthoptera (14). The less diversely represented orders were Phasmatodea (2), Hemiptera (2), Araneae (2) and Dermaptera (1). By frequency of occurrence, Diptera made up 23.9\%, while Coleoptera made up (20.8\%), Lepidoptera (17.7\%) and Orthoptera (14.6\%). Vertebrates (Squamata) represented a small portion of the diet, accounting for only $2 \%$ of the sequences obtained from gut content analysis (Table 1).

The relative abundance analysis of reads indicates that between 2 and a maximum of 64,287 reads were observed in each OTU. Of a total of 105,583 reads, $78.1 \%$ (82,537 reads) correspond to the order Orthoptera, 
followed by Diptera with $7.3 \%(7,776)$ and Blattodea with $6.4 \%(6,841)$. The remaining seven taxonomic orders represent only the remaining $8 \%$ of the reads in the diet of $P$. boliviensis . However, our results show a high dominance of reads for certain species. For example, the cricket of the genus Neoconocephalus (sp5) had the highest number of reads $(64,287$ ), which represented $60.8 \%$ of all reads (Supplementary Table S2 and Figure S2).

A total of 234 prey were identified, belonging to 96 different species in the 57 spiders sampled. The most abundant orders found as prey were Diptera (62) and Orthoptera (59). Six orthopteran species belonging to the genus Neoconocephalus were found, which were detected in 45 spiders, representing $19.2 \%$ of all registered prey items. For example, the OTU Neoconocephalus sp.5 (Orthoptera) is present in the diet of 32 of 57 spiders sampled. The preys with the second highest frequency were the two species of flies belonging to the genus Delia, which had a frequency of $9.8 \%$ of all prey (Table 1 ).

\section{Intersexual differences in prey composition ofPhoneutria boliviensis}

In this work, differences were identified in the consumption of prey between sexes of $P$. boliviensis. Of the 105,583 reads analyzed, $28.9 \%(30,516)$ correspond to prey detected in females and $71.1 \%(75,067)$ of the prey detected in males. For most orders, the number of reads of prey in males was more than double that of prey detected in females. Exclusive orders of a single genus were observed, as in the case of Squamata in females or Hemiptera in males (Supplementary Table S2). The prey-spider reads interaction network by sex is summarized in the Supplementary Figure S2, section a.

The greatest difference in the number of reads by prey between the sexes was found in the order Orthoptera. This order presents of $68.7 \%$ of reads in females compared with $82 \%$ in males. On the other hand, the results show us that of the total reads for this order $(82,537)$, the females represent $25.4 \%(20,961)$, while the males represent $74.6 \%(61,576)$ and Ibague represents $18.8 \%(15,517)$. When comparing the proportion of reads in the other taxonomic orders between the sexes, although they present significant differences between them $(\mathrm{P}=0,000)$, these are not as marked as those observed in Orthoptera. The prey-spider reads interaction network by sex is summarized in the Supplementary Figure S2, section a.

A total of 234 prey belonging to 96 different OTUs were observed, of which 108 prey were detected in females and 126 in males. The differences are mainly in the orders Orthoptera (females: 26 and males: 33), Lepidoptera (females: 7 and males: 17), Hemiptera (females: 0 and males: 2) and Squamata (females: 2 and males: 0). We identified 60 different prey species in females, while 65 different prey species were identified in males. Half (30) of the identified prey in the females are unique, while the other half (30) are shared by both sexes. Thirty-five species were observed as unique in males (Table 1). These results of the prey-spider species interaction network by sex is summarized in Figure 2.

\section{Interpopulation differences in prey composition ofPhoneutria boliviensis.}

Differences in the composition of diet in P. boliviensis were observed among the different populations. Of the 105,583 reads analyzed, $63.4 \%$ (66,970) correspond to prey detected in Barbosa, $13.1 \%(13,829)$ in Oporapa and $23.5 \%(24,784)$ of the prey detected in Ibague (Supplementary Table S2). The relative abundance of reads per sample and locality are shown in Figure 3.

The greatest difference between populations in reads per prey is observed in the order Orthoptera. For example, with respect to the total reads for each population, this order presented $90.3 \%$ in Barbosa, $46.9 \%$ in Oporapa and $62.5 \%$ in Ibague. On the other hand, the results showed that of the total reads for this order $(82,537)$, the population of Barbosa represents $73.4 \%$ (60,537), while Oporapa presented $7.8 \%(6,487)$ and Ibague 18.8\%. (15,513). Chi-square goodness-of-fit test show significant differences between reads of populations $(\mathrm{P}=0,000)$. The prey-spider reads interaction network by population is summarized in the Supplementary Figure S2, section b.

A total of 234 prey belonging to 96 different OTUs were observed, of which 70 were detected in Barbosa, 83 in Oporapa and 81 in Ibague. In terms of prey richness, Oporapa had the highest number of prey OTUs across individuals, followed by Ibague, and Barbosa, which was supported by the rarefaction curves (Figure 
4). The differences were mainly related to the orders Diptera ( $\mathrm{n}=14,20$ and 28 , respectively), Orthoptera $(\mathrm{n}=17,17$ and 25) and Coleoptera $(\mathrm{n}=11,24$ and 13). In Barbosa, 35.7\% $(\mathrm{n}=25)$ of the species identified as prey are unique, while in Oporapa it has $30.1 \%(\mathrm{n}=25)$ and Ibague with $23.5 \%(\mathrm{n}=19)$. Our results show that 21 to 26 spider prey species are shared between two or three spider populations (Table 1 ). The results of the prey-spider species interaction network by population is summarized in Figure 5.

\section{DISCUSSION}

\section{Diet of Phoneutria boliviensis}

In trophic ecology studies, it is not always possible to track trophic links between predators and prey by direct observation. This is especially critical when observing small, wandering, or elusive animals with nocturnal or cryptic food-web ecology (Sheppard and Harwood 2005). In this study, we developed a blocking primer pair (noSPI/dgHCO1) specifically designed for metabarcoding of gut contents of the spider $P$. boliviensis and phylogenetically closely related members of the Ctenidae family. Most studies based on molecular gutcontent analyses have focused on small-sized spider families such as the Linyphiidae (Agusti, et al. 2003; Macias-Hernandez, et al. 2018), Lycosidae (Eitzinger, et al. 2019; Lafage, et al. 2020; Zhong, et al. 2019), Theridiidae and Salticidae (Furlong, et al. 2014; Whitaker, et al. 2019), Tetragnathidae (Chapman, et al. 2010; Toju and Baba 2018) and Oxyopidae (Greenstone, et al. 2014). In these studies, the procedure of extraction was either homogenizing the whole spider or crushing the abdomen, taking into account the amount of sample and the size of the spider. The performance of the primer pair noSPI/dgHCO1 was compared in different body section samples of the spider, with the Prosoma+Opisthosoma sample showing the highest content of prey in P. boliviensis. Similar results were found in previous studies of other spider species, showing that this sampling of the body generally results in the largest prey content (Lafage, et al. 2020; Macias-Hernandez, et al. 2018). However, due to the use of blocking primes in our study, ctenid prey that were previously reported as prey for Phoneutria, such asSpinoctenus, Ctenus and Phoneutria are blocked (Valenzuela-Rojas, et al. 2020). This might explain the low number of spiders we found as prey in our analyses (see results).

Studies focusing on spider diet in natural habitats using metabarcoding are scarce, particularly for spider species that do not build an aerial web. Wirta et al. (Wirta, et al. 2015) found Pardosa glacialis to consume mainly Diptera and Lepidoptera in the High Arctic. Hamback, et al. (Hamback, et al. 2016) also found Diptera as the main prey of Pardosa prativaga followed by Lepidoptera, Coleoptera, and Heteroptera in the Baltic shoreline. Lafage et al. (Lafage, et al. 2020) found similar results to those observed here (up to 12 orders and 117 species) in Lycosidae species (genera tested: Pardosa, Trochosa, Hygrolycosa, Xerolycosa, and Pirata), using the same molecular technique. They also found Diptera, Hemiptera, Hymenoptera, and Lepidoptera as the main prey of different lycosid spiders. Similar results were also found in the wolf spiders of the genus Hygrolycosa and in multiple species of Pardosa, where Diptera are also the main component of the diet (Lafage, et al. 2020; Zhong, et al. 2019).

In a recent study of gut content analysis of four spider species of the genus Tetragnatha using DNA metabarcoding, Diptera, Hemiptera and Lepidoptera were observed to be the most frequent in the diet of these species in order of importance (Kennedy, et al. 2019). These results are strongly related with their capture strategy since the genus Tetragnatha builds webs to obtain its food. However, this kind of spiders is very small and web-building and therefore difficult to compare to the large, wandering P. boliviensis .

In this work, we determined a wide diversity of potential prey (up to 10 orders and 96 species) consumed by $P$. boliviensis through DNA metabarcoding analysis of gut contents; identifying prey belonging to the orders Diptera, Coleoptera, Lepidoptera and Orthoptera, principally. Our results show that P. boliviensis can consume, in addition to invertebrates, vertebrate species such as Anolis sp. (lizard) andStenorrhina sp. (snake). Some vertebrates have previously been reported as part of the P. boliviensis diet (Valenzuela-Rojas, et al. 2020; Valenzuela-Rojas, et al. 2019; Viera and Gonzaga 2017). For example, of the 57 spiders with gut contents identified, $52.6 \%$ (30) of them has at least one Diptera species as prey. According to our results, frequent consumption of some Diptera species could be considered as the basis of the diet of this spider. However, the study by Valenzuela-Rojas et al. (Valenzuela-Rojas, et al. 2020) reported no captures of 
Diptera, hypothesizing that $P$. boliviensis has a preference for larger prey. They identified prey up to three times larger than the size of the spider itself, which is contrary to our observations of a high preference for Diptera prey, which are small species between 4 to $13 \mathrm{~mm}$ long (Bartlett 2003).

We propose that at least three hypotheses that could explain the presence of Diptera as a prey for $P$. boliviensis .

a) Diptera as parasites of prey : Our analyses detected the presence of Diptera parasitoids, as in the case of Anisia(Stireman, et al. 2019) or Ogcodessp. (Kerr and Winterton 2008) and Tachina sp. (Sullivan and Ozman-Sullivan 2012) including spider parasites as in the case of Tachina sp. (Gillung and Borkent 2017; Sullivan and Ozman-Sullivan 2012). However, in our analysis, out of the 62 Diptera detected, only 3 (Anisia sp. (1), Ogcodes sp. (1) and Tachina sp. (1); see Table 1) would be parasitoids of other insects. Therefore, it does not lend support to a possible hypothesis that most of the Diptera species we detected were erroneously interpreted as prey but were actually present as parasitoids of arthropods preyed on by the spider. Similarly, in our analyses, several species of Hymenoptera were detected as prey. However, some of these species are reported as parasitoids, such as Mesochorus sp. (Ashfaq, et al. 2005) or predators of different insect species such as Vespula sp. (Pusceddu, et al. 2018). Among the parasitic Hymenoptera families detected from the spider samples, only Ichneumonidae includes well-characterized species known to parasitize on spiders (Eberhard 2000; Gauld and Dubois 2006).

b) Diptera and or Hymenoptera as parasites of the Phoneutriathemselves : Despite the frequent presence of parasitic insects in spiders, since most parasitoid hymenopterans and other parasitic Diptera (Gillung and Borkent 2017) detected in this study may be prey of the examined spiders; our spider samples did not seem to carry eggs/larvae/pupae of spider-specific Ichneumonidae wasps, which are easily recognizable ectoparasites (Eberhard 2000; Gauld and Dubois 2006).

c) Diptera (another insects) in the diet of the prey: We found a small number of prey species that are predators, as in the case of the spider Gonatium sp., which preys mainly on Coleoptera (Tamaddoni-Nezhad, et al. 2013); or the spider Neoscona sp. which preys mainly on Hemiptera (Xaaceph \& Butt, 2014). We also found predatory Coleoptera, as in the case of Agonum sp., Aleochara lata, Bembidion sp.,Saprinus sp., which prey on different insects (Battan Horenstein and Linhares 2011; Caron, et al. 2008; Riddick and Mills 1994; von Berg, et al. 2009). Similarly, we detected a species of Hemiptera of the genus Arma, which is reported as a predator of several insects (Zou, et al. 2012). Another explanation is the possible cannibalistic behavior of $P$. boliviensis towards juveniles or his own offspring, behavior reported in some scorpion species. This enables adults to collect food from prey that are usually too small for them (Polis 1980). If Phoneutria do the same, this could account for the higher number of small Diptera. Finally, within our samples of possible P. boliviensis prey, two reptile prey (Anolis sp. andStenorrhina sp.) were detected, which are reported mainly as insectivores (Barragan-Contreras and Calderon-Espinosa 2013; Shewchuk and Austin 2001). Of the 234 prey identified in $P$. boliviensis, only 24 (see Table 1) are insect predators or parasitoids; therefore, we consider that a possible false prey event would be low, but cannot be ruled out. Unfortunately, DNA metabarcoding analysis alone cannot indicate whether such parasitoids are directly preyed on by spiders or were just parasitizing on insect hosts caught by spiders (Toju and Baba 2018). According to Toju and Baba (Toju and Baba 2018), existing DNA barcoding methods, including those presented in this work, are not designed to distinguish between signs of cannibalism, intra-guild predation, scavenging, and secondary predation (i.e., DNA of a prey's prey). Despite these limitations, DNA metabarcoding is a powerful tool for systematically investigating prey compositions of a whole spider community because many spider species are nocturnal, as P. boliviensis (Bucaretchi, et al. 2016), making their predation behavior difficult to observe directly in the field (Fenk, et al. 2010; Toju and Baba 2018).

d) Bias in previous studies : In a recent observational study on the diet of $P$. boliviensis in the field, diet was composed predominantly of arthropods (86\%) and to a lesser extent, small vertebrates (14\%), consuming 21 different species (Valenzuela-Rojas, et al. 2020). According to Valenzuela-Rojas, et al. (2020) the natural diet of P. boliviensis included individuals of the orders Araneae, Blattodea, Coleoptera, Hymenoptera, Lepidoptera, Mantodea, Orthoptera, and Phasmatodea. Furthermore, the diet of this spider is shown to 
include lizards (Gekkonidae and Sphaerodactylidae) and frogs (Hylidae). According to the authors, the prey of $P$. boliviensis was larger than the spiders themself, and predation was not observed of prey items larger than three times the body length of $P$. boliviensis . Our results, as well as the previous reports, confirm that $P$. boliviensis has a generalist polyphagous diet. However, in the study conducted by Valenzuela-Rojas et al. (Valenzuela-Rojas, et al. 2020), contrary to our results, no captures of Diptera were observed as a prey of this spider. The difference between the observational studies and the studies of analysis of gut content by DNA metabarcoding appears to be the latter's greater sensitivity in the detection of prey (Liu, et al. 2020; Pompanon, et al. 2012). This was exemplified again here in the case of Diptera. DNA metabarcoding presents the same limitations as observational fieldwork studies in species identification, especially in tropical regions with high biodiversity (Barsoum, et al. 2019; Liu, et al. 2020). However, in DNA metabarcoding, species identification can be automated in a high-throughput way, given a sufficiently diverse reference database. Likewise, Diptera (and other small-sized insects such as some coleopteran species), may be missing from previous studies because they were all carried out at night, while diptera are mostly diurnal. Additionally, these insects are small, and consumed fast, reducing the likelihood that they are encountered while being consumed.

Despite all the advantages of prey detection using DNA metabarcoding, and the large number of arthropod species with DNA barcodes $(246,069)$ in the Barcode of Life Data Systems (BOLD) (Ratnasingham and Hebert 2007), the low representativity of sequences from South America (Colombia with only 39,741 of 9,265,546 Specimen Records; accessed June 2020) reduces the likelihood that sequences are correctly assigned, which may lead to not identifying sequences of 77 species (identified only at the order level) of prey that were in the gut contents of the spider.

According to recent studies, DNA metabarcoding is mostly used to detect the presence of species in samples rather than their relative abundance, although sequence frequency is sometimes used as a proxy of species abundance (Aizpurua, et al. 2018; Deagle, et al. 2019). Several studies have demonstrated positive relationships between input species biomass and output sequencing reads. For example, Bista et al. (Bista, et al. 2018) detected a strong positive correlation $\left(R^{2}=0.83\right)$ between biomass input and read abundance by DNA metabarcoding for the beetleGyrinus marinus . Therefore, based on our analyses of relative abundance of reads of prey, the most abundant taxonomic groups were Orthoptera, Diptera and Blattodea, respectively (see Supplementary Table S2 and Figure S2), which could mean that the highest biomass associated with stomach content in P. boliviensis would be associated mainly with the cricket of the genus Neoconocephalus and the species of Diptera detected as prey. On the other hand, according to Sint et al. (Sint, et al. 2011; Sint, et al. 2015), the molecular detection of prey in spiders has a high sensitivity up to 84-h post-feeding; which would explain both the high number of prey per spider detected in this work (234), and the variation in the reads of the same prey species (i.e., the cricket of the genusNeoconocephalus, detected in 37/57 spider' guts).

\section{Differences between males and females}

In most animals, males and females show marked differences in primary and secondary sexual traits. The sexual dimorphism literature pertaining to invertebrates is fragmented, particularly for arachnids (McLean, et al. 2018). Spiders are sexually dimorphic in various morphological, behavioral, and life history traits (Cordellier, et al. 2020). Our study provides evidence for both sexual dimorphism (significant differences in mass between females and males), and a different trophic ecology in males and females of P. boliviensis. We identified that the males on average are smaller than the females; however, we found that some males are larger than some females. Adult male and female spiders generally differ in body weight, but they can be of similar size and shape or differ markedly, depending on species (Cordellier, et al. 2020). These analyses would suggest that a differential trophic environment could affect this character (see above for our analysis by location).

We found sexual differences in diet in our analysis of gut contents of $P$. boliviensis. Our results show that of the total reads, $28.9 \%$ are present in females and $71.1 \%$ detected in males. We also found a lower number of preys in females than in males (108 and 126, respectively). In a study on wolf spiders, differences in 
predatory behavior were observed between males and females (Persons and Uetz 1999). In this study, it was observed that male wolf spiders travel greater distances, with greater hunting efforts compared to females. In addition, other factors such as the amount of venom produced and toxicity of the venom differ between the sexes in this species (Valenzuela-Rojas, et al. 2019). This in turn could influence, or be an adaptation to, differences in the diet, for example the consumption of vertebrates by females (Table 1).

Our results show that wild female $P$. boliviensis prey on vertebrates. Different studies under laboratory conditions have shown the tendency of $P$. boliviensis to be a euryphagus given its great voracity, as well as its capacity to consume small vertebrates (Valenzuela-Rojas, et al. 2019). Through the analysis of gut contents by metabarcoding, these findings are corroborated in the wild.

The difference in the number of intakes of prey or variety of food items is usually attributed to differences in size, either total size or specific structures such as pedipalps or carapace (Foellmer and Moya-Larano 2007). Body size dimorphism may be the result of selection for many factors, such as reproductive success, hyper-predation, dispersal capacity among others (Crawley 2009). In our results, males are smaller than females and also have a greater number of prey items than females, which supports the hypothesis that in spiders with sexual dimorphism a larger size does not necessarily imply that a greater range of prey can be captured (McLean, et al. 2018). Similarly, the capacity to consume certain prey is influenced by multiple factors, not only morphological differences between sexes, but also differential predatory behavior and the active search for females by males to reproduce (Kotiaho, et al. 1998). The toxicity of $P$. boliviensis venom is higher in males than in females, which could ensure greater success in hunting, without ruling out the possibility that it is used defensively (Valenzuela-Rojas, et al. 2019).

\section{Differences between populations}

Although the number of prey items among the Barbosa, Oporapa and Ibague populations are very similar (70, 83 and 81, respectively), differences exist in the type of prey. When comparing the diet in P. boliviensis among populations, the diversity (number of species) of Coleoptera was higher in Oporapa, representing twice as many items as the other two populations studied. Furthermore, it was the only population where the order Dermaptera was consumed, while in Ibague the most consumed order was Diptera followed by Orthoptera. Finally, Barbosa was the locality with the lowest number of prey species. The three localities present differences in the prey species that compose the diet, which may indicate that the selection of prey species may be in good part be determined by their availability (Birkhofer and Wolters 2012; Eitzinger, et al. 2019; Hamback, et al. 2016). Nevertheless, the analysis of relative read counts by population shows that spiders from Barbosa have two or three times more reads than the populations of Oporapa and Ibague. One hypothesis that could explain this behavior would be that larger spiders have a greater prey capacity. However, our results do not identify a clear correlation $\left(\mathrm{R}^{2}=0,003\right)$ between read count per population and the body size of the spider (in term of fresh mass).

The proportions of each order of prey show marked differences between populations, especially in the order Orthoptera. These differences between populations may be influenced by the availability of prey in each population, and these in turn are influenced by biogeographical characteristics such as the Andes mountain range that crosses the populations and could affect the ranges of certain prey species, as well as factors such as temperature, humidity and anthropogenic pressures (Ramirez-Villegas, et al. 2014). According to the environmental data of relative humidity, temperature and altitude, some differences are observed between the populations (see Supplementary Table S1), which would justify the differences between them at the trophic level.

\section{CONCLUSIONS}

This project contributed to the knowledge of the trophic ecology of $P$. boliviensis using the DNA metabarcoding approach, confirming its Euryphagous feeding behavior. We show a wider range of prey species than reported previously for this species in Colombia. Some prey species are reported here for the first time. Our results also could be the first evidence that males of $P$. boliviensis apparently have a greater hunting effort, as indicated by an increased number of prey and reads compared to females. This suggests different 
predatory strategies between the sexes, perhaps based on different energy requirements. Similarly, there is a small difference in trophic ecology depending on the locality (comparing our records of diet composition and taxa richness), again confirming the generalist nature and flexibility of the diet. However, our results differ from previous findings using different diet assessment techniques in the field and the laboratory (ValenzuelaRojas et al., 2019, 2020). Particularly the high fraction of Diptera in the diet we found could not have been anticipated based on these previous findings and requires further corroboration. In addition, it is necessary to extend the studies with DNA barcoding in South America, in order to identify, at the species level, the possible prey and the ecological impact of this predatory spider.

\section{ACKNOWLEDGEMENTS}

We thank the University of Ibague and University of Tolima for supporting this research. We are grateful to the Departamento Administrativo de Ciencia, Tecnologia e Innovacion (Colciencias-Currently Minciencias, Colombia) for financial support for this project (ID Project 130780864623). The first author thanks to Oficina de Investigaciones y Desarrollo Cientifico de la Universidad del Tolima by the early researcher scholarship. We thanks to Roberto Builes, Alexander Cuervo, Eliana Loaiza and Francisco Chavarro by their field work assistance. Specimens collected are covered through the Colombian "Permiso Marco de Recoleccion", granted to the Universidad de Ibague (Resolucion no. 01003, 07 June 2019, Autoridad Nacional de Licencias Ambientales -ANLA). All laboratory procedures were followed in agree the Ethical Code approved for the above Minciencias' project. AvdM was financed through FCT - Fundacao para a Ciencia e a Tecnologia, I.P. under contract number DL57/2016/CP1440/CT0009.

\section{AUTHORS' CONTRIBUTIONS}

DS-R: Methodology, spiders collecting, mass measures of the spiders, data processing, statistical processing, construction, and revision of the manuscript.

GG: Conceptualization, methodology, execution of diversity analysis, statistical analysis, review of the manuscript.

LM-FP: Conceptualization, methodology, construction, and review of the manuscript.

A-VDM: Conceptualization, and review of the manuscript.

JCG-G: Spiders collecting, mass measures of the spiders, review, and comments on the draft.

JCV-R: Spiders collecting, review and comments on the draft.

CF-PQ: Conceptualization methodology, data processing, construction, and revision of the manuscript.

Data Accessibility

Sampling locations, OTUS Phoneutria prey, Spider Prey Diversity, The relative abundance of reads per sample and locality data and statistical input files: Dryad doi: 10.5061/dryad.9zw3r22bt

\section{REFERENCES}

Agusti N, Shayler SP, Harwood JD, Vaughan IP, Sunderland KD, Symondson WO 2003. Collembola as alternative prey sustaining spiders in arable ecosystems: prey detection within predators using molecular markers. Mol Ecol 12: 3467-3475. doi: 10.1046/j.1365-294x.2003.02014.x

Aizpurua O, Budinski I, Georgiakakis P, Gopalakrishnan S, Ibanez C, Mata V, Rebelo H, Russo D, SzodorayParadi F, Zhelyazkova V, Zrncic V, Gilbert MTP, Alberdi A 2018. Agriculture shapes the trophic niche of a bat preying on multiple pest arthropods across Europe: Evidence from DNA metabarcoding. 27: 815-825. doi: 10.1111/mec.14474

Arend D 2010. Minitab 17-Statistical Software; State College, PA: Minitab. Inc.[Google Scholar]. 
Ashfaq M, Erlandson M, Braun L 2005. Hyperparasitism by Mesochorus spp.(Hymenoptera: Ichneumonidae) in Peristenus sp.(Hymenoptera: Braconidae) and development of PCR primers for hyperparasitoid detection. Biological Control 32: 371-377. doi: 10.1016/j.biocontrol.2004.11.007

Barragan-Contreras LA, Calderon-Espinosa ML 2013. What do Anolis eat?: evaluation of sexual dimorphism and geographic variation in the diet of Anolis ventrimaculatus (Squamata: dactyloidae) in Colombia. Actualidades Biologicas 35: 199-208.

Barsoum N, Bruce C, Forster J, Ji Y-Q, Douglas WY 2019. The devil is in the detail: Metabarcoding of arthropods provides a sensitive measure of biodiversity response to forest stand composition compared with surrogate measures of biodiversity. Ecological Indicators 101: 313-323. doi: 10.1016/j.ecolind.2019.01.023

Bartlett T 2003. BugGuide. Net: Identification, Images, \& Information For Insects, Spiders \& Their Kin For the United States \& Canada.

Battan Horenstein M, Linhares AX 2011. Seasonal composition and temporal succession of necrophagous and predator beetles on pig carrion in central Argentina. Med Vet Entomol 25: 395-401. doi: 10.1111/j.13652915.2011.00969.x

Betz L, Tscharntke T 2017. Enhancing spider families and spider webs in Indian rice fields for conservation biological control, considering local and landscape management. Journal of Insect Conservation 21: 495-508. doi: 10.1007/s10841-017-9990-2

Birkhofer K, Bylund H, Dalin P, Ferlian O, Gagic V, Hamback PA, Klapwijk M, Mestre L, Roubinet E, Schroeder M, Stenberg JA, Porcel M, Bjorkman C, Jonsson M 2017. Methods to identify the prey of invertebrate predators in terrestrial field studies. Ecol Evol 7: 1942-1953. doi: 10.1002/ece3.2791

Birkhofer K, Wolters V 2012. The global relationship between climate, net primary production and the diet of spiders. Global Ecology and Biogeography 21: 100-108. doi: 10.1111/j.1466-8238.2011.00654.x

Bista I, Carvalho GR, Tang M, Walsh K, Zhou X, Hajibabaei M, Shokralla S, Seymour M, Bradley D, Liu S, Christmas M, Creer S 2018. Performance of amplicon and shotgun sequencing for accurate biomass estimation in invertebrate community samples. Mol Ecol Resour. doi: 10.1111/1755-0998.12888

Bucaretchi F, Bertani R, De Capitani E, Hyslop S 2016. Envenomation by wandering spiders (Genus Phoneutria). Clin. Tox 63: 1-49. doi: 10.1007/978-94-007-6288-6

Bucherl W, Buckley EE, Deulofeu V. 2013. Venomous Animals and Their Venoms: Venomous Vertebrates: Elsevier.

Caron E, Mise KM, Klimaszewski J 2008. Aleochara pseudochrysorrhoa, a new species from southern Brazil (Coleoptera: Staphylinidae: Aleocharinae), with a complete checklist of Neotropical species of the genus. Revista Brasileira de Zoologia 25: 827-842. doi: 10.1590/s0101-81752008000400022

Cordellier M, Schneider JM, Uhl G, Posnien N 2020. Sex differences in spiders: from phenotype to genomics. 230: 155-172. doi: 10.1007/s00427-020-00657-6

Chao A, Gotelli NJ, Hsieh T, Sander EL, Ma K, Colwell RK, Ellison AM 2014. Rarefaction and extrapolation with Hill numbers: a framework for sampling and estimation in species diversity studies. Ecological monographs 84: 45-67. doi: 10.1890/13-0133.1

Chapman EG, Romero SA, Harwood JD 2010. Maximizing collection and minimizing risk: does vacuum suction sampling increase the likelihood for misinterpretation of food web connections? Mol Ecol Resour 10: 1023-1033. doi: 10.1111/j.1755-0998.2010.02857.x

de Sena Brandine G, Smith AD 2019. Falco: high-speed FastQC emulation for quality control of sequencing data. F1000Research 8: 1874. doi: 10.12688/f1000research.21142.1 
Deagle BE, Thomas AC, McInnes JC, Clarke LJ, Vesterinen EJ, Clare EL, Kartzinel TR, Eveson JP 2019. Counting with DNA in metabarcoding studies: How should we convert sequence reads to dietary data? Mol Ecol 28: 391-406. doi: 10.1111/mec.14734

Eberhard WG 2000. Spider manipulation by a wasp larva. Nature 406: 255-256. doi: 10.1038/35018636

Edgar RC 2010. Search and clustering orders of magnitude faster than BLAST. Bioinformatics 26: 24602461. doi: 10.1093/bioinformatics/btq461

Eitzinger B, Abrego N, Gravel D, Huotari T, Vesterinen EJ, Roslin T 2019. Assessing changes in arthropod predator-prey interactions through DNA-based gut content analysis-variable environment, stable diet. 28: 266-280. doi: $10.1111 /$ mec. 14872

Estrada-Gomez S, Munoz LJ, Lanchero P, Latorre CS 2015. Partial Characterization of Venom from the Colombian Spider Phoneutria Boliviensis (Aranae:Ctenidae). Toxins (Basel) 7: 2872-2887. doi: 10.3390/toxins7082872

Federhen S 2012. The NCBI Taxonomy database. Nucleic Acids Res 40: D136-143. doi: $10.1093 /$ nar/gkr1178

Fenk LM, Hoinkes T, Schmid A 2010. Vision as a third sensory modality to elicit attack behavior in a nocturnal spider. J Comp Physiol A Neuroethol Sens Neural Behav Physiol 196: 957-961. doi: 10.1007/s00359010-0575-8

Foelix R. 2011. Biology of spiders: OUP USA.

Foellmer MW, Moya-Larano J 2007. Sexual size dimorphism in spiders: patterns and processes. Sex, size and gender roles: Evolutionary studies of sexual size dimorphism: 71-81.

Furlong MJ, Rowley DL, Murtiningsih R, Greenstone MH 2014. Combining ecological methods and molecular gut-content analysis to investigate predation of a lepidopteran pest complex of B rassica crops. Entomologia Experimentalis et Applicata 153: 128-141. doi: 10.1111/eea.12231

Garcia L, Franco V, Robledo-Ospina L, Viera C, Lacava M, Willemart R 2016. The predation strategy of the recluse spider Loxosceles rufipes (Lucas, 1834) against four prey species. Journal of insect behavior 29: 515-526. doi: 10.1007/s10905-016-9578-9

Garcia LF, Viera C, Pekar S 2018. Comparison of the capture efficiency, prey processing, and nutrient extraction in a generalist and a specialist spider predator. Naturwissenschaften 105: 30. doi: 10.1007/s00114$018-1555-\mathrm{z}$

Gauld ID, Dubois J 2006. Phylogeny of the Polysphincta group of genera (Hymenoptera: Ichneumonidae; Pimplinae): a taxonomic revision of spider ectoparasitoids. Systematic Entomology 31: 529-564. doi: 10.1111/j.1365-3113.2006.00334.x

Gillung JP, Borkent CJ 2017. Death comes on two wings: a review of dipteran natural enemies of arachnids. The Journal of Arachnology 45: 1-19. doi: 10.1636/joa-s-16-085.1

Greenstone MH, Tillman PG, Hu JS 2014. Predation of the newly invasive pest Megacopta cribraria (Hemiptera: Plataspidae) in soybean habitats adjacent to cotton by a complex of predators. J Econ Entomol 107: 947-954. doi: 10.1603/ec13356

Hamback PA, Weingartner E, Dalen L, Wirta H, Roslin T 2016. Spatial subsidies in spider diets vary with shoreline structure: Complementary evidence from molecular diet analysis and stable isotopes. Ecol Evol 6: 8431-8439. doi: 10.1002/ece3.2536

Hazzi NA 2014. Natural history of Phoneutria boliviensis (Araneae: Ctenidae): habitats, reproductive behavior, postembryonic development and prey-wrapping. The Journal of Arachnology 42: 303-310. doi: 10.1111/j.1469-185x.1982.tb00363.x 
Herzig V, John Ward R, Ferreira dos Santos W 2002. Intersexual variations in the venom of the Brazilian 'armed' spider Phoneutria nigriventer (Keyserling, 1891). Toxicon 40: 1399-1406. doi: 10.1016/s00410101(02)00136-8

Hsieh T, Ma K, Chao A 2016. iNEXT: an R package for rarefaction and extrapolation of species diversity (H ill numbers). Methods in Ecology and Evolution 7: 1451-1456. doi: 10.1111/2041-210X.12613

Jackson RR, Pollard SD, Nelson XJ, Edwards G, Barrion AT 2001. Jumping spiders (Araneae: Salticidae) that feed on nectar. Journal of Zoology 255: 25-29. doi: 10.1017/S095283690100108X

Kennedy S, Lim JY, Clavel J, Krehenwinkel H, Gillespie RG 2019. Spider webs, stable isotopes and molecular gut content analysis: multiple lines of evidence support trophic niche differentiation in a community of Hawaiian spiders. Functional Ecology 33: 1722-1733. doi: 10.1111/1365-2435.13361

Kerr PH, Winterton SL 2008. Do parasitic flies attack mites? Evidence in Baltic amber. Biological Journal of the Linnean Society 93: 9-13. doi: 10.1111/j.1095-8312.2007.00935.x

Kotiaho JS, Alatalo RV, Mappes J, Nielsen MG, Parri S, Rivero A 1998. Energetic costs of size and sexual signalling in a wolf spider. Proceedings of the Royal Society of London. Series B: Biological Sciences 265: 2203-2209. doi: 10.1098/rspb.1998.0560

Kress WJ, Erickson DL 2007. A two-locus global DNA barcode for land plants: the coding rbcL gene complements the non-coding trnH-psbA spacer region. PLoS One 2: e508. doi: 10.1371/journal.pone.0000508

Lafage D, Elbrecht V, Cuff JP, Steinke D, Hamback PA, Erlandsson A 2020. A new primer for metabarcoding of spider gut contents. Environmental DNA 2: 234-243. doi: 10.1002/edn3.62

Leidenfrost RM, Bansch S, Prudnikow L, Brenig B, Westphal C, Wunschiers R 2020. Analyzing the Dietary Diary of Bumble Bee. Front Plant Sci 11: 287. doi: 10.3389/fpls.2020.00287

Leray M, Yang JY, Meyer CP, Mills SC, Agudelo N, Ranwez V, Boehm JT, Machida RJ 2013. A new versatile primer set targeting a short fragment of the mitochondrial COI region for metabarcoding metazoan diversity: application for characterizing coral reef fish gut contents. Frontiers in zoology 10: 34. doi: 10.1186/1742-9994-10-34

Lima SL 1998. Nonlethal effects in the ecology of predator-prey interactions. Bioscience 48: 25-34. doi: $10.2307 / 1313225$

Liu M, Clarke LJ, Baker SC, Jordan GJ, Burridge CP 2020. A practical guide to DNA metabarcoding for entomological ecologists. Ecological entomology 45: 373-385. doi: 10.1111/een.12831

Macias-Hernandez N, Athey K, Tonzo V, Wangensteen OS, Arnedo M, Harwood JD 2018. Molecular gut content analysis of different spider body parts. PLoS One 13: e0196589. doi: 10.1371/journal.pone.0196589

McLean CJ, Garwood RJ, Brassey CA 2018. Sexual dimorphism in the Arachnid orders. PeerJ 6: e5751. doi: $10.7717 /$ peerj. 5751

Michalek O, Petrakova L, Pekar S 2017. Capture efficiency and trophic adaptations of a specialist and generalist predator: A comparison. Ecol Evol 7: 2756-2766. doi: 10.1002/ece3.2812

Michalko R, Pekar S, Entling MH 2019. An updated perspective on spiders as generalist predators in biological control. Oecologia 189: 21-36. doi: 10.1007/s00442-018-4313-1

Nyffeler M 1999. Prey selection of spiders in the field. Journal of Arachnology: 317-324.

Nyffeler M, Olson EJ, Symondson WO 2016. Plant-eating by spiders. Journal of Arachnology: 15-27. doi: $10.1636 / \mathrm{p} 15-45.1$

Pekar S, Sobotnik J, Lubin Y 2011. Armoured spiderman: morphological and behavioural adaptations of a specialised araneophagous predator (Araneae: Palpimanidae). Naturwissenschaften 98: 593-603. doi: 


\subsection{7/s00114-011-0804-1}

Pekar S, Toft S 2015. Trophic specialisation in a predatory group: the case of prey-specialised spiders (Araneae). Biol Rev Camb Philos Soc 90: 744-761. doi: 10.1111/brv.12133

Pentinsaari M, Blagoev GA, Hogg ID, Levesque-Beaudin V, Perez K, Sobel CN, Vandenbrink B, Borisenko A 2020. A DNA Barcoding Survey of an Arctic Arthropod Community: Implications for Future Monitoring. Insects 11: 46. doi: 10.3390/insects11010046

Persons MH, Uetz GW 1999. Age and sex-based differences in the use of prey sensory cues in wolf spiders (Araneae: Lycosidae). Journal of insect behavior 12: 723-736. doi: 10.1023/A:1020920024954

Pinol J, Senar MA, Symondson WOC 2019. The choice of universal primers and the characteristics of the species mixture determine when DNA metabarcoding can be quantitative. Mol Ecol 28: 407-419. doi: 10.1111/mec. 14776

Polis GA 1980. The effect of cannibalism on the demography and activity of a natural population of desert scorpions. Behavioral Ecology and Sociobiology 7: 25-35. doi: 10.1007/BF00302515

Pompanon F, Deagle BE, Symondson WO, Brown DS, Jarman SN, Taberlet P 2012. Who is eating what: diet assessment using next generation sequencing. Mol Ecol 21: 1931-1950. doi: 10.1111/j.1365294X.2011.05403.x

Pompozzi G, Garcia LF, Petrakova L, Pekar S 2019. Distinct feeding strategies of generalist and specialist spiders. Ecological entomology 44: 129-139. doi: 10.1111/een.12683

Portalier SM, Fussmann GF, Loreau M, Cherif M 2019. The mechanics of predator-prey interactions: First principles of physics predict predator-prey size ratios. Functional Ecology 33: 323-334. doi: 10.1111/13652435.13254

Pusceddu M, Mura A, Floris I, Satta A 2018. Feeding strategies and intraspecific competition in German yellowjacket (Vespula germanica). 13: e0206301. doi: 10.1371/journal.pone.0206301

R Development Core t 2018. A Language ans Environment for Statistical Computing. R Found Stat Comput Vienna, Austria 2.

Ramirez-Villegas J, Cuesta F, Devenish C, Peralvo M, Jarvis A, Arnillas CA 2014. Using species distributions models for designing conservation strategies of Tropical Andean biodiversity under climate change. Journal for Nature Conservation 22: 391-404. doi: 10.1016/j.jnc.2014.03.007

Ratnasingham S, Hebert PD 2007. bold: The Barcode of Life Data System (http://www.barcodinglife.org). Mol Ecol Notes 7: 355-364. doi: 10.1111/j.1471-8286.2007.01678.x

Riddick EW, Mills NJ 1994. Potential of adult carabids (Coleoptera: Carabidae) as predators of fifth-instar codling moth (Lepidoptera: Tortricidae) in apple orchards in California. Environmental Entomology 23: 1338-1345. doi: 10.1093/ee/23.5.1338

Rognes T, Flouri T, Nichols B, Quince C, Mahe F 2016. VSEARCH: a versatile open source tool for metagenomics. PeerJ 4: e2584. doi: 10.7717/peerj.2584

Sang T, Crawford D, Stuessy T 1997. Chloroplast DNA phylogeny, reticulate evolution, and biogeography of Paeonia (Paeoniaceae). Am J Bot 84: 1120. doi: 10.2307/2446155

Schmitz OJ 2007. Predator diversity and trophic interactions. Ecology 88: 2415-2426. doi: 10.1890/060937.1

Seibold S, Cadotte MW, MacIvor JS, Thorn S, Muller J 2018. The Necessity of Multitrophic Approaches in Community Ecology. Trends Ecol Evol 33: 754-764. doi: 10.1016/j.tree.2018.07.001 
Severtsov A, Shubkina A 2015. Predator-prey interaction between individuals: 1. The role of predators in natural selection. Biology Bulletin 42: 633-642. doi: 10.1134/S1062359015070080

Sheppard S, Harwood J 2005. Advances in molecular ecology: tracking trophic links through predator-prey food-webs. Functional Ecology 19: 751-762. doi: 10.1111/j.1365-2435.2005.01041.x

Shewchuk CH, Austin JD 2001. Food habits of the racer (Coluber constrictor mormon) in the northern part of its range. Herpetological Journal 11: 151-156.

Sint D, Raso L, Kaufmann R, Traugott M 2011. Optimizing methods for PCR-based analysis of predation. Mol Ecol Resour 11: 795-801. doi: 10.1111/j.1755-0998.2011.03018.x

Sint D, Thurner I, Kaufmann R, Traugott M 2015. Sparing spiders: faeces as a non-invasive source of DNA. Front Zool 12: 3. doi: 10.1186/s12983-015-0096-y

Start D, Weis AE, Gilbert B 2020. Ecological and Evolutionary Stochasticity Shape Natural Selection. Am Nat 195: 705-716. doi: 10.1086/707364

Stireman JO, 3rd, Cerretti P, O'Hara JE, Blaschke JD, Moulton JK 2019. Molecular phylogeny and evolution of world Tachinidae (Diptera). Mol Phylogenet Evol 139: 106358. doi: 10.1016/j.ympev.2018.12.002

Sullivan G, Ozman-Sullivan S 2012. Tachinid (Diptera) parasitoids of Hyphantria cunea (Lepidoptera: Arctiidae) in its native North America and in Europe and Asia-a literature review. Entomologica Fennica 23: 181-192-181-192. doi: 10.33338/ef.7384

Symondson WO, Sunderland KD, Greenstone MH 2002. Can generalist predators be effective biocontrol agents? Annu Rev Entomol 47: 561-594. doi: 10.1146/annurev.ento.47.091201.145240

Tamaddoni-Nezhad A, Milani GA, Raybould A, Muggleton S, Bohan DA. 2013. Construction and validation of food webs using logic-based machine learning and text mining. In. Advances in Ecological Research: Elsevier. p. 225-289.

Toju H, Baba YG 2018. DNA metabarcoding of spiders, insects, and springtails for exploring potential linkage between above- and below-ground food webs. Zoological Lett 4: 4. doi: 10.1186/s40851-018-0088-9

Valdez J 2020. Arthropods as Vertebrate Predators: A Review of Global Patterns. Journal of Chemical Information and Modeling, 53: 1689-1699. doi: 10.1017/CBO9781107415324.004

Valenzuela-Rojas JC, Gonzalez-Gomez JC, Guevara G, Franco LM, Reinoso-Florez G, Garcia LF 2020. Notes on the feeding habits of a wandering spider, Phoneutria boliviensis (Arachnida: Ctenidae). The Journal of Arachnology 48: 43-48. doi: 10.1636/0161-8202-48.1.43

Valenzuela-Rojas JC, Gonzalez-Gomez JC, van der Meijden A, Cortes JN, Guevara G, Franco LM, Pekar S, Garcia LF 2019. Prey and Venom Efficacy of Male and Female Wandering Spider, Phoneutria boliviensis (Araneae: Ctenidae). Toxins (Basel) 11: 622. doi: 10.3390/toxins11110622

Vetter RS, Isbister GK 2008. Medical aspects of spider bites. Annu Rev Entomol 53: 409-429. doi: 10.1146/annurev.ento.53.103106.093503

Viera C, Gonzaga MO. 2017. Behaviour and Ecology of Spiders: contributions from the Neotropical Region: Springer.

von Berg K, Thies C, Tscharntke T, Scheu S 2009. Cereal aphid control by generalist predators in presence of belowground alternative prey: complementary predation as affected by prey density. Pedobiologia 53: 41-48. doi: 10.1016/j.pedobi.2009.03.001

Whitaker MR, Baker CC, Salzman SM, Martins DJ, Pierce NE 2019. Combining stable isotope analysis with DNA metabarcoding improves inferences of trophic ecology. PLoS One 14: e0219070. doi: 10.1371/journal.pone. 0219070 
Wirta HK, Weingartner E, Hamback PA, Roslin T 2015. Extensive niche overlap among the dominant arthropod predators of the High Arctic. Basic and Applied Ecology 16: 86-92. doi: 10.1016/j.baae.2014.11.003

Zhong W, Tan Z, Wang B, Yan H 2019. Next-generation sequencing analysis of Pardosa pseudoannulata's diet composition in different habitats. Saudi J Biol Sci 26: 165-172. doi: 10.1016/j.sjbs.2018.08.004

Zou D, Wang M, Zhang L, Zhang Y, Zhang X, Chen H 2012. Taxonomic and bionomic notes on Arma chinensis (Fallou)(Hemiptera: Pentatomidae: Asopinae). Zootaxa 3382: 41-52. doi: 10.11646/zootaxa.3382.1.4

\section{List of tables and figures}

Table 1. The diet of spider Phoneutria boliviensis from Colombia identified by DNA metabarcoding. Number of taxa corresponds to those identified to species, genera and family level by sex and populations (= locality).

Figure 1. Colombian locations selected for sampling and collecting specimens of Phoneutria boliviensis .

Figure 2. Intersex bipartite prey-spider species interaction network. Lines connect the males and females (left) to dietary species OTUs (bottom, colored by taxonomic order). The length of the boxes on the left reflects the number of prey analyzed for each OTU; the length of the boxes on the right reflects the relative abundance of each prey per OTU in each taxonomic order of prey in all samples in the data set; and the width of the connecting lines reflects the relative reads abundance of each OTU within the diet of each taxonomic order. We show only the connections that represent [?]1\% of the diet of each species (total $\mathrm{n}=234$ OTUs). a) Araneae, b) Blattodea, c) Coleoptera, d) Dermaptera, e) Diptera, f) Hemiptera, g) Hymenoptera, h) Lepidoptera, i) Orthoptera, j) Phasmatodea, k) Squamata.

Figure 3. The relative abundance of reads per sample and locality. The boxes on the x-axis represent each individual by population. The different colors represent the relative abundance of reads for each taxonomic order.

Figure 4. Sample-based rarefaction curves of prey richness (q0) in the three Colombian populations of P. boliviensis, denoted by the three colors. Line types indicate whether estimates are interpolated (solid) or extrapolated (dashed). Ribbons indicate the $95 \%$ confidence intervals (CIs) obtained by the bootstrap method based on 1000 replications.

Figure 5. Interpopulation bipartite prey-spider species interaction network. Lines connect the Barbosa, Oporapa and Ibague localities (left) to dietary OTUs (bottom, colored by taxonomic order). The length of the boxes on the left reflects the number of prey analyzed for each OTU. The length of the boxes on the right reflects the relative abundance of each prey per OTU in each taxonomic order of prey in all samples in the data set, and the width of the connecting lines reflects the relative reads abundance of each OTU within the diet of each taxonomic order. We show only the connections that represent [?]1\% of the diet of each species (total $\mathrm{n}=234$ OTUs). a) Araneae, b) Blattodea, c) Coleoptera, d) Dermaptera, e) Diptera, f) Hemiptera, g) Hymenoptera, h) Lepidoptera, i) Orthoptera, j) Phasmatodea, k) Squamata.

\section{Supplementary Material}

Table S1. Elevation, temperature, relative humidity and mass data in the sampled localities.

Table S2. Diet of $P$. boliviensis identified by DNA metabarcoding. Number of reads at species and order levels.

Figure S1. Comparison of the fresh mass of $P$. boliviensis showing differences between sexes and between populations. Values indicate mean $+-95 \%$ CI $(\mathrm{n}=10)$.

Figure S2. Bipartite prey-spider reads interaction network. a) analysis by sex, b) analysis by population. Lines connect the gender or populations (left) to 10 dietary order species OTUs (bottom, colored by taxonomic order). The length of the boxes on the left reflects the number of reads analyzed for each OTU. The length of the boxes on the right reflects the relative abundance of each read per OTU in each taxonomic 
order of prey in all samples in the data set, and the width of the connecting lines reflects the relative reads abundance of each OTU within the diet. We show only the connections that represent [?]1\% of the diet of each species (total $\mathrm{n}=105,583$ reads).

Table 1. The diet of spider Phonuetria boliviensis from Colombia identified by DNA metabarcoding. Number of species corresponds to those identified to species, genera and family level by gender and populations. (-) undata

\begin{tabular}{|c|c|c|c|c|c|c|c|c|c|}
\hline & & Female & Male & & Total gender & Barbosa & Total & Oporapa & Total \\
\hline Order & Specie & Count & Count & & & Count & & Count & \\
\hline \multirow[t]{2}{*}{ Araneae } & Gonatium sp & 1 & 0 & 1 & 7 & 0 & 2 & 0 & 1 \\
\hline & Neoscona sp. & 1 & 5 & 6 & & 2 & & 1 & \\
\hline \multirow[t]{9}{*}{ Blattodea } & Blattella sp. & 1 & 0 & 1 & 13 & 0 & 4 & 1 & 6 \\
\hline & Cryptocercus sp. & 0 & 1 & 1 & & 0 & & 1 & \\
\hline & Epilampra sp. & 1 & 0 & 1 & & 1 & & 0 & \\
\hline & Epilamprinae sp. & 1 & 0 & 1 & & 0 & & 1 & \\
\hline & Nyctibora_sp. & 1 & 0 & 1 & & 0 & & 1 & \\
\hline & Periplaneta $\mathrm{sp} 1$ & 1 & 4 & 5 & & 2 & & 1 & \\
\hline & Periplaneta $\mathrm{sp} 2$ & 1 & 0 & 1 & & 0 & & 0 & \\
\hline & Pycnoscelus surinamensis & 1 & 0 & 1 & & 1 & & 0 & \\
\hline & Rhabdoblatta sp & 0 & 1 & 1 & & 0 & & 1 & \\
\hline \multirow[t]{20}{*}{ Coleoptera } & Agonum sp. & 2 & 0 & 2 & 48 & 1 & 11 & 1 & 24 \\
\hline & Aleochara_lata & 0 & 1 & 1 & & 0 & & 1 & \\
\hline & Aphodius sp. & 0 & 1 & 1 & & 0 & & 1 & \\
\hline & Bembidion sp. & 2 & 0 & 2 & & 0 & & 2 & \\
\hline & Brachygonus sp. & 0 & 1 & 1 & & 0 & & 0 & \\
\hline & Carabus sp1. & 8 & 8 & 16 & & 3 & & 8 & \\
\hline & Carabus sp2. & 1 & 0 & 1 & & 0 & & 1 & \\
\hline & Carabus sp3. & 0 & 1 & 1 & & 0 & & 0 & \\
\hline & Carpelimus sp. & 0 & 1 & 1 & & 1 & & 0 & \\
\hline & Chauliognathus sp. & 0 & 1 & 1 & & 0 & & 1 & \\
\hline & Creophilus maxillosus & 0 & 1 & 1 & & 0 & & 0 & \\
\hline & Cyclocephala sp. & 1 & 1 & 2 & & 1 & & 0 & \\
\hline & Entiminae sp. & 1 & 1 & 2 & & 0 & & 1 & \\
\hline & Necrobia rufipes & 3 & 2 & 5 & & 1 & & 2 & \\
\hline & Ptinus sp. & 1 & 0 & 1 & & 0 & & 1 & \\
\hline & Saprinus sp1 & 1 & 1 & 2 & & 2 & & 0 & \\
\hline & Saprinus sp2 & 3 & 1 & 4 & & 1 & & 2 & \\
\hline & Thanatophilus sp1 & 1 & 1 & 2 & & 1 & & 1 & \\
\hline & Thanatophilus sp2 & 0 & 1 & 1 & & 0 & & 1 & \\
\hline & Tribolium_castaneum & 0 & 1 & 1 & & 0 & & 1 & \\
\hline Dermaptera & Forficula auricularia & 2 & 2 & 4 & 4 & 0 & 0 & 4 & 4 \\
\hline \multirow[t]{10}{*}{ Diptera } & Anisia sp. & 0 & 1 & 1 & 62 & 1 & 14 & 0 & 20 \\
\hline & Chironomus sp. & 0 & 1 & 1 & & 0 & & 0 & \\
\hline & Corynoneura sp. & 1 & 0 & 1 & & 1 & & 0 & \\
\hline & Delia platura & 6 & 7 & 13 & & 3 & & 4 & \\
\hline & Delia sp & 4 & 6 & 10 & & 4 & & 2 & \\
\hline & Fannia sp & 2 & 1 & 3 & & 0 & & 2 & \\
\hline & Helina sp1 & 0 & 1 & 1 & & 0 & & 1 & \\
\hline & Helina sp2 & 1 & 2 & 3 & & 0 & & 2 & \\
\hline & Helina_evecta & 1 & 1 & 2 & & 0 & & 1 & \\
\hline & Lucilia sp. & 0 & 1 & 1 & & 0 & & 1 & \\
\hline
\end{tabular}




\begin{tabular}{|c|c|c|c|c|c|c|c|c|c|}
\hline & & Female & Male & & Total gender & Barbosa & Total & Oporapa & Total \\
\hline & Lucilia sp2 & 1 & 0 & 1 & & 0 & & 0 & \\
\hline & Lutzomyia sp & 0 & 1 & 1 & & 1 & & 0 & \\
\hline & Ogcodes sp. & 0 & 1 & 1 & & 0 & & 0 & \\
\hline & Phaonia sp1 & 1 & 0 & 1 & & 0 & & 1 & \\
\hline & Phaonia sp2 & 1 & 0 & 1 & & 1 & & 0 & \\
\hline & Phaonia sp3 & 1 & 0 & 1 & & 0 & & 1 & \\
\hline & Pipunculus campestris & 1 & 1 & 2 & & 0 & & 1 & \\
\hline & Polypedilum sp. & 0 & 1 & 1 & & 0 & & 0 & \\
\hline & Ravinia sp. & 1 & 0 & 1 & & 0 & & 0 & \\
\hline & Sarcophaga sp1 & 2 & 1 & 3 & & 1 & & 0 & \\
\hline & Sarcophaga sp2 & 4 & 3 & 7 & & 1 & & 3 & \\
\hline & Sarcophaga sp3 & 3 & 2 & 5 & & 1 & & 1 & \\
\hline & Tachina sp. & 1 & 0 & 1 & & 0 & & 0 & \\
\hline \multirow[t]{2}{*}{ Hemiptera } & Arma sp. & 0 & 1 & 1 & 2 & 1 & 1 & 0 & 1 \\
\hline & Draeculacephala sp. & 0 & 1 & 1 & & 0 & & 1 & \\
\hline \multirow[t]{4}{*}{ Hymenoptera } & Azteca_quadraticeps & 0 & 1 & 1 & 4 & 0 & 3 & 1 & 1 \\
\hline & Mesochorus sp. & 1 & 0 & 1 & & 1 & & 0 & \\
\hline & Pheidole sp4 & 1 & 0 & 1 & & 1 & & 0 & \\
\hline & Vespula sp. & 0 & 1 & 1 & & 1 & & 0 & \\
\hline \multirow[t]{17}{*}{ Lepidoptera } & Agriphila sp. & 1 & 3 & 4 & 24 & 1 & 10 & 3 & 8 \\
\hline & Arctiinae sp. & 1 & 0 & 1 & & 1 & & 0 & \\
\hline & Chrysodeixis includens & 0 & 1 & 1 & & 1 & & 0 & \\
\hline & Elysius sp. & 0 & 1 & 1 & & 0 & & 1 & \\
\hline & Gonodonta sp. & 1 & 1 & 2 & & 1 & & 0 & \\
\hline & Hypena & 0 & 1 & 1 & & 0 & & 1 & \\
\hline & Leucania dorsalis & 1 & 1 & 2 & & 1 & & 0 & \\
\hline & Leucania inconspicua & 0 & 1 & 1 & & 0 & & 1 & \\
\hline & Lymantria sp. & 1 & 1 & 2 & & 1 & & 0 & \\
\hline & Melipotis fasciolaris & 0 & 1 & 1 & & 0 & & 0 & \\
\hline & Mocis sp. & 0 & 1 & 1 & & 1 & & 0 & \\
\hline & Perissopteryx & 0 & 1 & 1 & & 1 & & 0 & \\
\hline & Pero sp. & 1 & 1 & 2 & & 0 & & 1 & \\
\hline & Prochoerodes sp. & 0 & 1 & 1 & & 1 & & 0 & \\
\hline & Pseudaletia sequax & 0 & 1 & 1 & & 0 & & 1 & \\
\hline & Rosema dorsalis & 1 & 0 & 1 & & 1 & & 0 & \\
\hline & Spodoptera frugiperda & 0 & 1 & 1 & & 0 & & 0 & \\
\hline \multirow[t]{14}{*}{ Orthoptera } & Abracris sp1. & 0 & 1 & 1 & 59 & 0 & 17 & 1 & 17 \\
\hline & Abracris sp2 & 1 & 2 & 3 & & 0 & & 2 & \\
\hline & Abracris sp3 & 1 & 1 & 2 & & 0 & & 1 & \\
\hline & Abracris sp4 & 1 & 0 & 1 & & 0 & & 0 & \\
\hline & Conocephalus saltator & 1 & 2 & 3 & & 1 & & 2 & \\
\hline & Lebinthus sp. & 2 & 0 & 2 & & 0 & & 0 & \\
\hline & Neoconocephalus affinis & 2 & 1 & 3 & & 0 & & 2 & \\
\hline & Neoconocephalus sp1 & 0 & 2 & 2 & & 2 & & 0 & \\
\hline & Neoconocephalus sp2 & 1 & 1 & 2 & & 1 & & 0 & \\
\hline & Neoconocephalus sp3 & 4 & 0 & 4 & & 4 & & 0 & \\
\hline & Neoconocephalus sp4 & 0 & 2 & 2 & & 0 & & 0 & \\
\hline & Neoconocephalus sp5 & 11 & 21 & 32 & & 9 & & 9 & \\
\hline & Vilerna_sp. & 1 & 0 & 1 & & 0 & & 0 & \\
\hline & Xyleus sp. & 1 & 0 & 1 & & 0 & & 0 & \\
\hline
\end{tabular}




\begin{tabular}{llllllllll}
\hline & & Female & Male & & Total gender & Barbosa & Total & Oporapa & Total \\
\hline Phasmatodea & Libethra sp. & 4 & 4 & 8 & 9 & 6 & 7 & 1 & 1 \\
& Metriophasma & 1 & 0 & 1 & & 1 & & 0 & \\
Squamata & Anolis sp. & 1 & 0 & 1 & 2 & 1 & 1 & 0 & 0 \\
Total & Stenorrhina sp. & 1 & 0 & 1 & & 0 & & 0 & \\
\hline
\end{tabular}

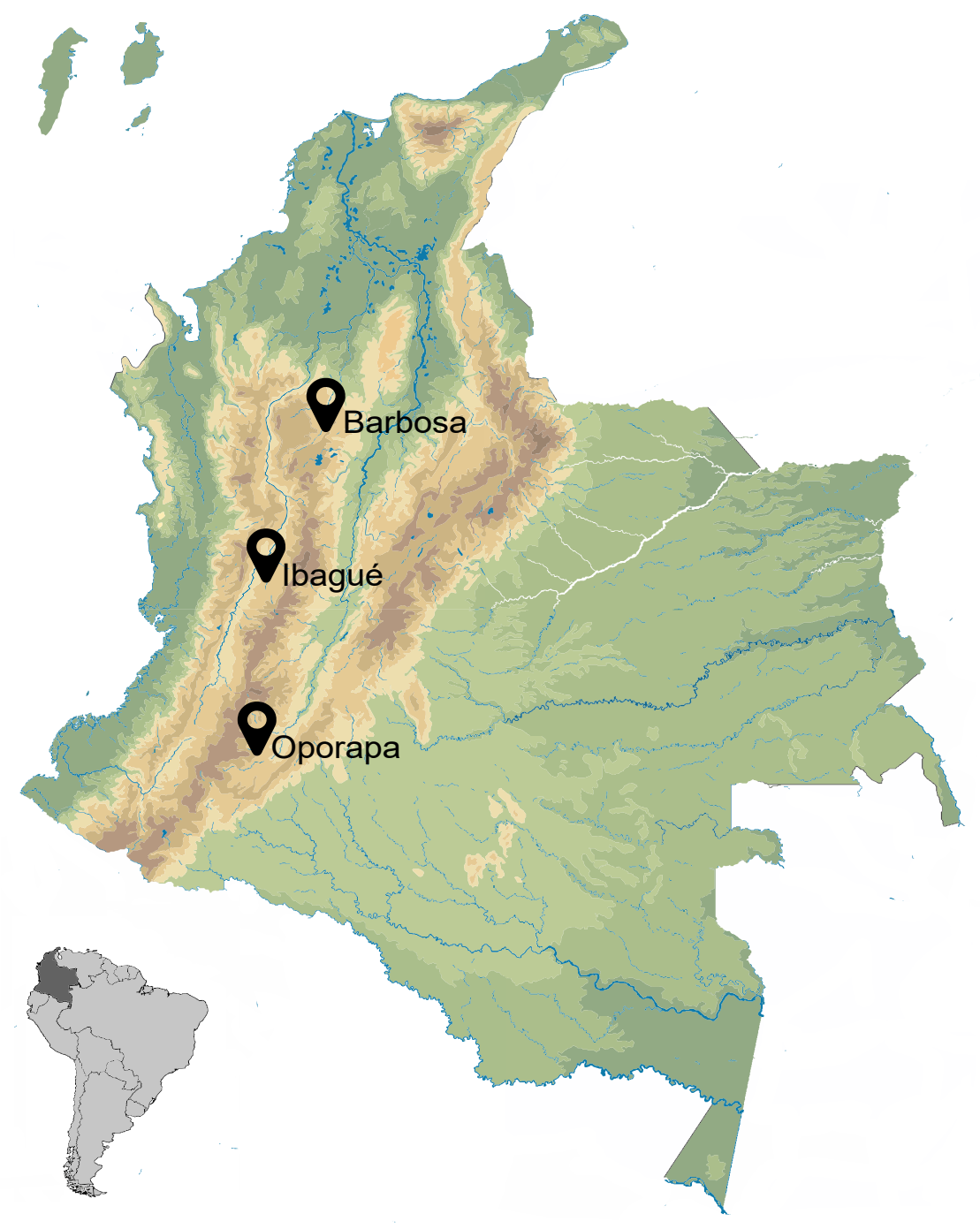




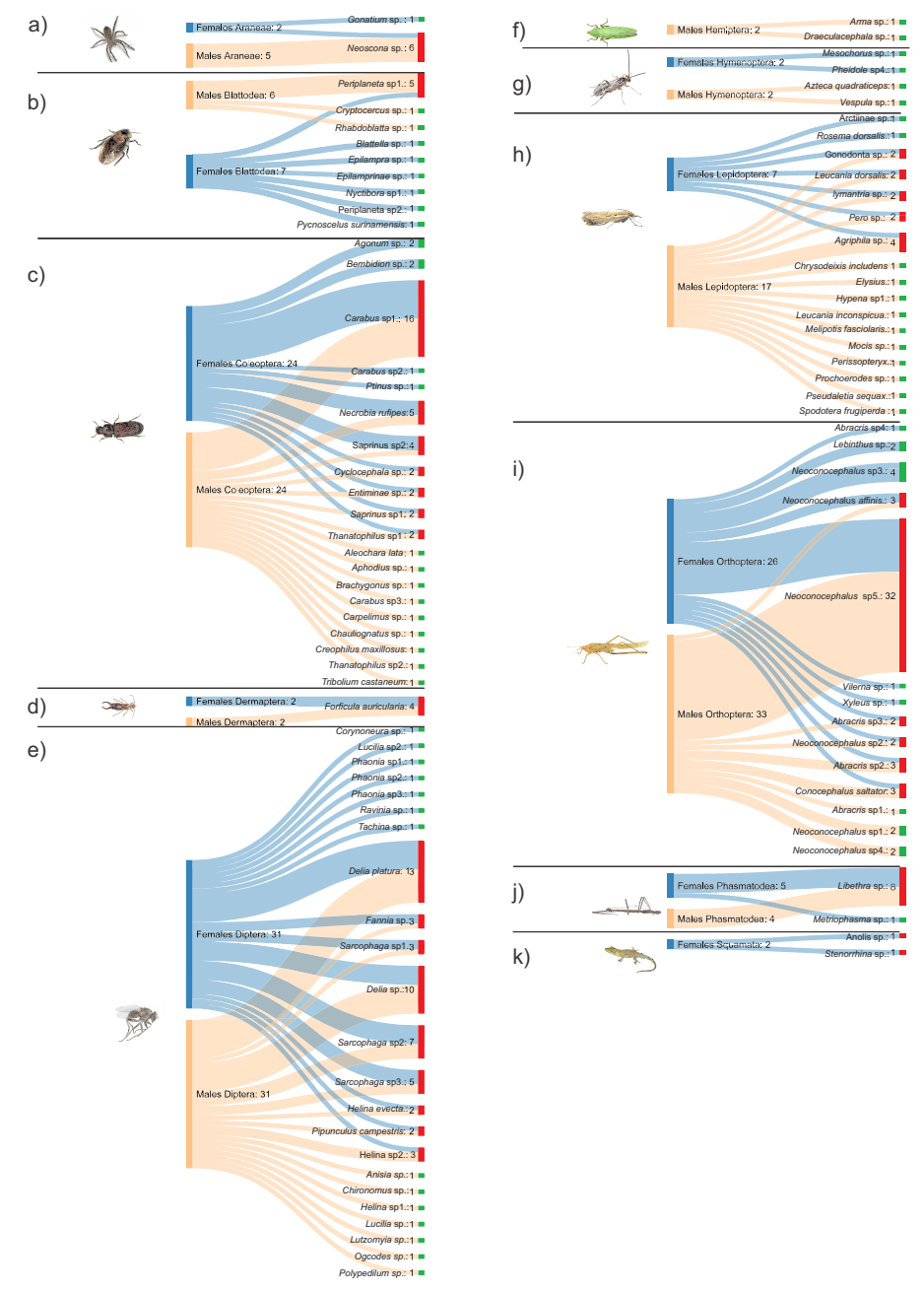



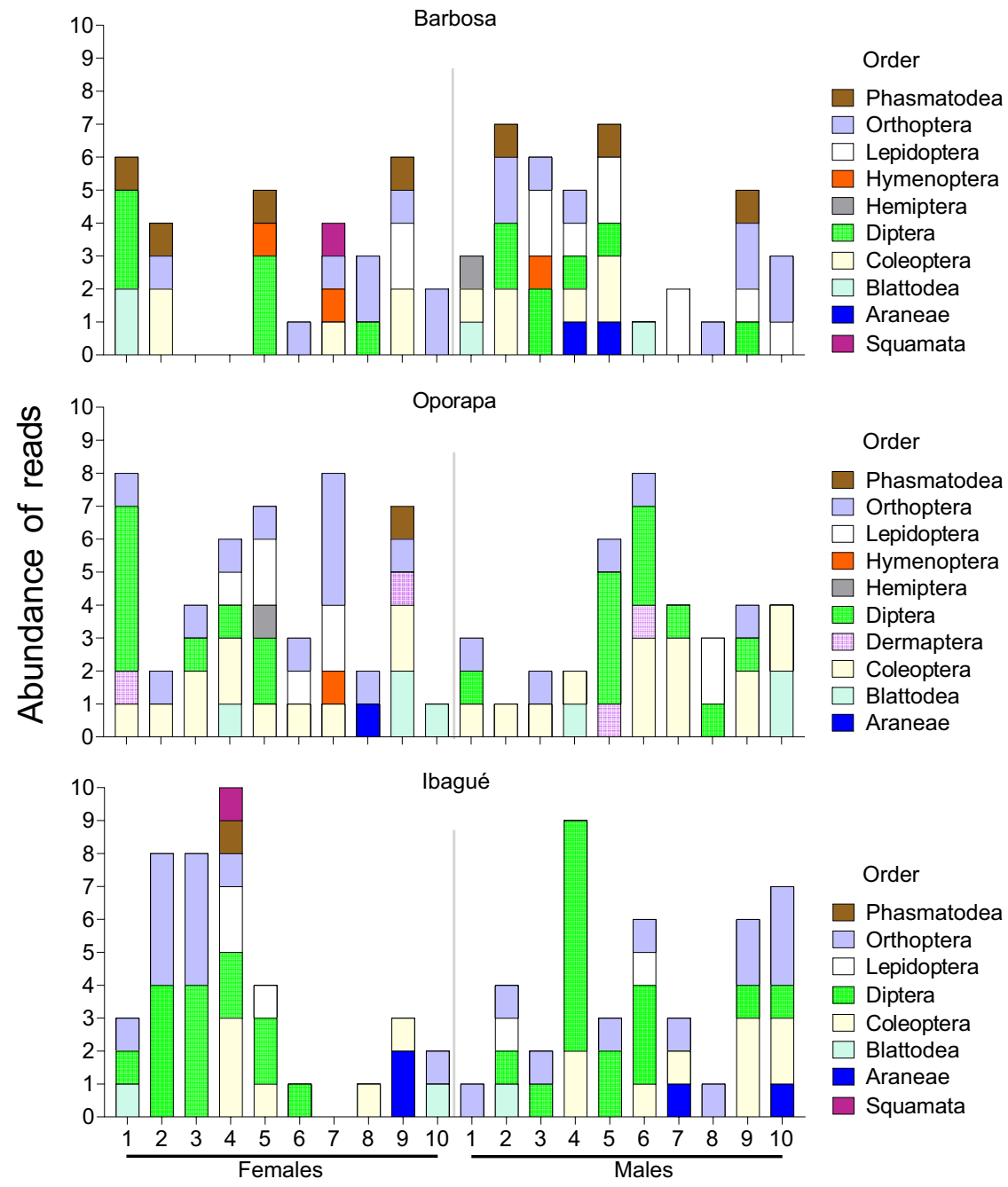


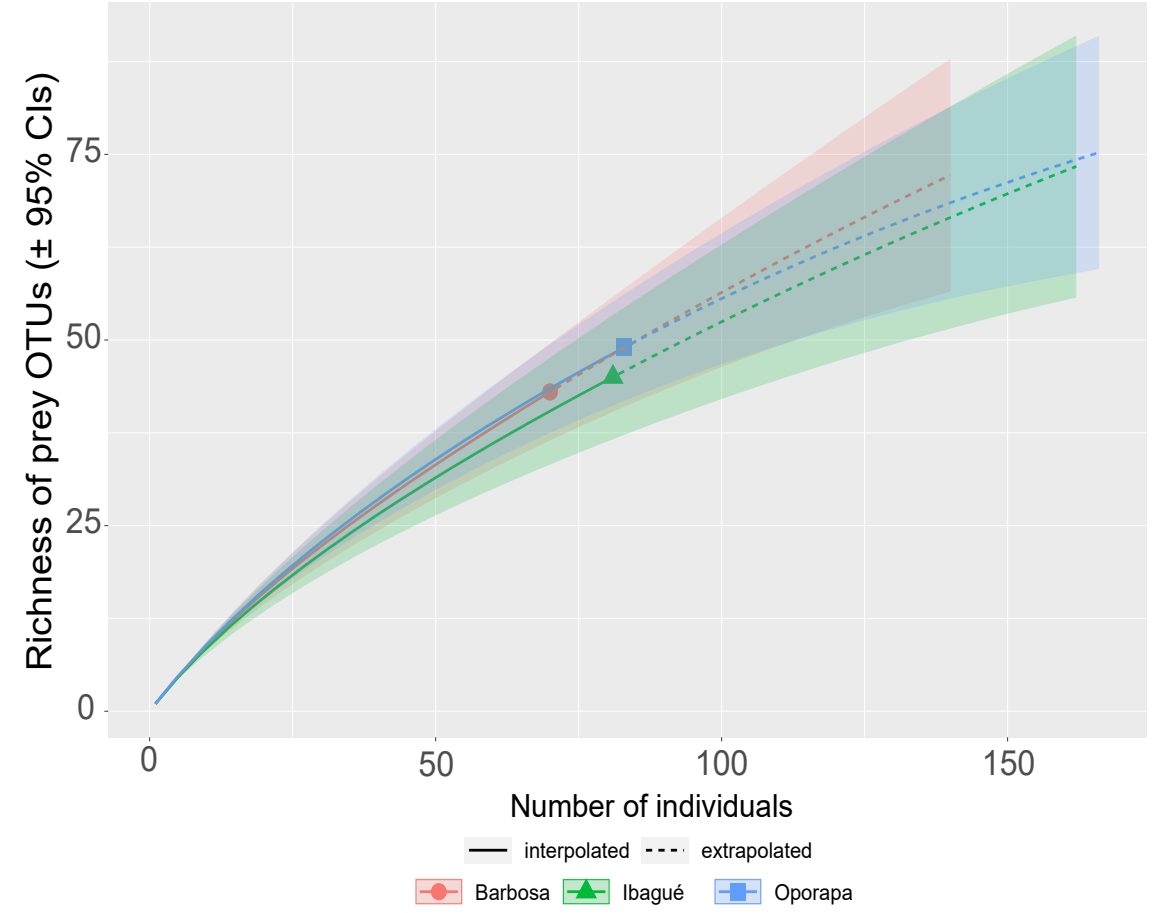


a)

b)

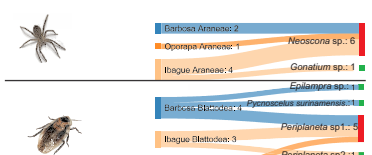

c)
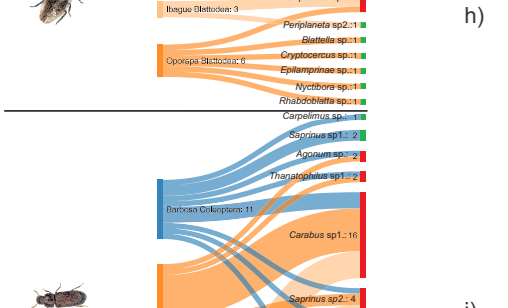

h)

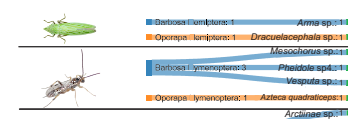

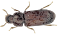

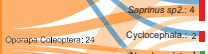

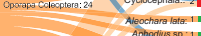

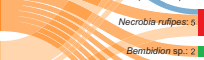

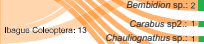

d)

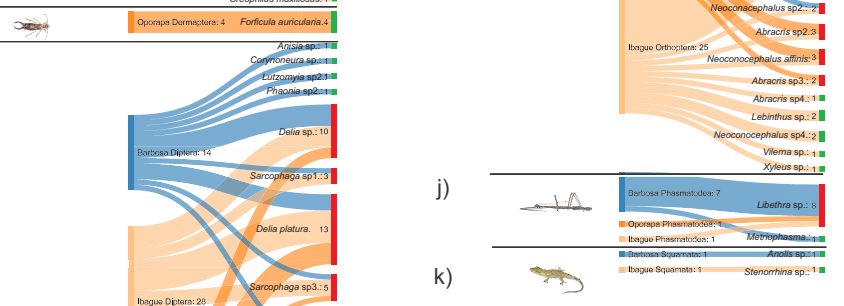

e) 